\title{
Scalable Techniques for Producing Field Effect Passivation in High-Efficiency Silicon Solar Cells
}

\author{
Katherine A. Collett, Student Member, IEEE, Siyao Du, Gabrielle Bourret-Sicotte, Student Member, \\ IEEE, Zhaohua Luo, Phillip Hamer, Member, IEEE, Brett Hallam, Ruy S. Bonilla, and Peter R.
}

Wilshaw

\begin{abstract}
This work presents techniques to tailor and optimize field effect passivation of silicon surfaces using the deposition and field-assisted migration of potassium ions. While field effect passivation of this nature has previously been demonstrated using laboratory scale techniques, in this work it is shown how it can be realised using fast and scalable ion deposition and migration methods. Together, the deposition and migration processes are seen to produce excellent improvements to the surface passivation of oxidised $1 \mathbf{\Omega} \mathrm{cm}$ n-type float-zone silicon. Effective lifetimes as high as $\mathbf{2 . 1} \mathbf{~ m s}$ are observed, in the best case yielding a surface recombination velocity as low as $3.3 \mathrm{~cm} / \mathrm{s}$ with a corresponding surface dark saturation current density of $8.4 \mathrm{fA} / \mathrm{cm}^{2}$.
\end{abstract}

Index Terms - Silicon photovoltaics, surface passivation, field effect passivation, ion charged dielectrics.

\section{INTRODUCTION}

$\mathrm{I}$ $\mathrm{N}$ order to maximise the performance of silicon solar cells, 1 the unwanted recombination of photo-generated carriers must be minimised [1]. One of the key areas where recombination occurs is the surface of crystalline silicon, where an abundance of band-gap defect levels act as effective recombination centres. There are two mechanisms to reduce

This work was supported by the EPSRC (UK) Postdoctoral Research Fellowship, EP/M022196/1 and grant EP/M024911/1. The authors would like to thank Radka Chakalova for her extensive help in the Oxford cleanroom. All authors are thankful to Stuart Erickson at Ultrasonic Systems, Inc. and Mark Higgins at S3-Alliance for ion spraying of specimens.

K. A. Collett (katherine.collett@materials.ox.ac.uk),

G. Bourret-Sicotte (gabrielle.bourret-sicotte@materials.ox.ac.uk),

SiyaoDu (siyao.du@stcatz.ox.ac.uk),

P. Hamer (phillip.hamer@materials.ox.ac.uk),

R. S. Bonilla (sebastian.bonilla@materials.ox.ac.uk) and

P. R. Wilshaw (peter.wilshaw@materials.ox.ac.uk)

are with the Department of Materials, University of Oxford, Parks Rd, Oxford, OX1 3PH, UK.

B. Hallam (brett.hallam@unsw.edu.au) and P. Hamer are with the School of Photovoltaic and Renewable Energy Engineering, University of New South Wales, Sydney, New South Wales 2052, Australia

Zhaohua Luo is with the Ningbo Institute of Materials Engineering and Technology, Chinese Academy of Sciences, Zhejiang, 315201, China. (email: luozhaohua@nimte.ac.cn) such recombination. Firstly, the density of defect levels can be decreased, known as chemical passivation. Chemical passivation is provided by a dielectric layer, which doubles as an antireflection coating. This can be supplemented by the introduction of hydrogen through a forming gas anneal (FGA) [2], shielded hydrogen passivation (SHP) [3], or during the industry-standard fast-firing of metal contacts which releases hydrogen from the dielectric layer [4].

Secondly, the access of minority carriers to defect levels can be limited. This is termed field effect passivation (FEP) because an electric field is used to control the surface carrier concentration [5]. FEP is most commonly provided by charge in the dielectric; most dielectric films have some degree of intrinsic charge. However, this is usually not optimal. In order to address this, it has been shown that charge added extrinsically, after deposition or growth, can significantly reduce surface recombination. For example, the addition of corona charge to an as-received oxide surface increases the surface passivation lowering the surface recombination velocity (SRV) from $100 \mathrm{~cm} / \mathrm{s}$ to $1.5 \mathrm{~cm} / \mathrm{s}$ [6]. Unfortunately, the stability of corona charge is unsuitable for commercial solar cells, which must maintain their performance for over 30 years [6]-[8]. A more stable alternative is the introduction of ionic species to dielectric layers, where they have been found to provide very effective FEP, and potassium-ion passivation showed a decay time constant exceeding 40 years under laboratory conditions [9]. It is noted that previous work by Hezel et al. [10]-[12] demonstrated stable passivation using spin coated cesium ions and silicon nitride deposition.

Techniques suitable for large-scale manufacture must be fast, scalable and fit for processing full-size $\left(\sim 240 \mathrm{~cm}^{2}\right)$ silicon solar cells with a throughput of $\sim 3600$ wafers per hour. There are two important criteria for a method to introduce ionic charge into a dielectric. First, the precursor must be deposited in uniform, sub-monolayer concentrations, the reasons for which are discussed in Section III. Second, the technique must be both rapid and scalable. In this paper, industrially applicable techniques for introducing ionic FEP are outlined and studied. The deposition of ion precursors onto the silicon dioxide surface is carried out through spin or spray coating. These processes are easily scaled to be large area and high throughput, making them highly compatible with industry 
requirements. The deposition process is followed by ion migration, shown here to be possible in a matter of seconds using corona charge field-assisted drift. Corona charge deposition is a widely used technique being applied, for example, in laser printers [13], [14].

The deposition technique also has the potential to be deployed to large-scale in-line cell production. Here it is shown that these new processes can be as effective at producing FEP as the laboratory technique previously reported [9], [15]. Although these processes are un-optimized, the initial results are extremely promising, showing SRV reductions from $101 \mathrm{~cm} / \mathrm{s}$ to $3.3 \mathrm{~cm} / \mathrm{s}$, with an equivalent surface dark saturation current density $\left(\mathrm{J}_{0 \mathrm{~s}}\right)$ of $8.4 \mathrm{fA} / \mathrm{cm}^{2}$.

\section{EXPERIMENTAL MethodS}

Double-side polished, $200 \mu \mathrm{m}$ thick, phosphorous doped 1 $\Omega \mathrm{cm}$ n-type FZ silicon substrates were used. A $100 \mathrm{~nm}$ thermal oxide was grown on this silicon at Fraunhofer ISE at $1050{ }^{\circ} \mathrm{C}$ in a $\mathrm{O}^{2} / \mathrm{DCE}$ atmosphere. The samples did not undergo a forming gas anneal. In this work, $100 \mathrm{~nm}$ oxides were used to boost the detection of charge using capacitancevoltage and Kelvin Probe measurements. It is noted that the findings presented here should be comparable for $10 \mathrm{~nm}$ or thinner oxides, which are often used for commercial solar cells [16], [17]. Samples were cleaved to be $3 \mathrm{~cm} \times 3 \mathrm{~cm}$.

The overall processing sequence is shown in Fig 1. The ionic precursor was deposited by thermal evaporation, spin or spray coating, as denoted by the blue boxes in Fig 1. Because the majority of samples were intended for effective lifetime measurements, processing was done symmetrically. Therefore, ionic precursor was deposited on both sides of the sample, as was corona discharge for migration. For thermal evaporation, DI water was used as a solvent for a solution of $\mathrm{KCl}$ suitable to produce an ionic surface concentration of $2 \pm 1 \times 10^{14}$ ions $/ \mathrm{cm}^{2}$ as detailed in [9]. This concentration was confirmed using Thermally Stimulated Ionic Conduction (TSIC) measurements of a metal-oxide-semiconductor (MOS) structure fabricated from the ion deposited oxide, using ebeam deposited aluminium as the gate metal. Details of TSIC can be found in [18], [19].

For spin coating, $\mathrm{KCl}$ was dissolved in $25 / 75 \%$ vol $\mathrm{H}_{2} \mathrm{O} / \mathrm{IPA}$. $2 \mathrm{~mL}$ of $4.4 \times 10^{-5} \mathrm{~mol} / \mathrm{L} \mathrm{KCl}$ solution was pipetted onto the sample once the spinner was at $2000 \mathrm{RPM}$. This concentration was chosen with the aim of achieving a surface ionic concentration of $6 \times 10^{12}$ ions $/ \mathrm{cm}^{2}$. Spray coating was conducted at USI, Haverhill MA, using a PRISM bench-top ultrasound coating system. A solution of $3 \times 10^{-4} \mathrm{~mol} / \mathrm{L} \mathrm{KCl}$ in $10 / 90 \%$ vol $\mathrm{H}_{2} \mathrm{O} / \mathrm{IPA}$ was used to produce an $11 \mu \mathrm{m}$ thick wet layer on the sample, before drying. This was predicted to give a surface ionic concentration of $10^{14}$ ions $/ \mathrm{cm}^{2}$, however TSIC processing on aluminium MOS structures determined the maximum concentration of $\mathrm{K}$ ions deposited to be $\sim 10^{13}$. ions $/ \mathrm{cm}^{2}$.

Migration was assisted by corona discharge from a single pin at $30 \mathrm{kV}$ situated $20 \mathrm{~cm}$ above the specimen surface. The concentration of surface corona charge was inferred using
Kelvin Probe (KP) measurements. This process was followed by a hotplate anneal at temperatures between $250-450{ }^{\circ} \mathrm{C}$, in an air ambient in a non-cleanroom laboratory. The purpose of the anneal is to provide kinetic energy to accelerate the rate of ion injection. To reduce contamination, and support experiments at higher temperatures, a borosilicate glass petridish with lid was placed on top of a hotplate. This allowed the atmosphere inside the petri-dish to reach a higher temperature than if the sample was placed directly on the hotplate. The temperature inside the petri-dish with the lid in place was measured using a thermocouple. When placing the sample inside the petri dish the lid was quickly removed causing a decrease in temperature, which recovered within $\sim 5$ seconds. At $450{ }^{\circ} \mathrm{C}$, the reduction in temperature was $\sim 10{ }^{\circ} \mathrm{C}$. During the one or two minute anneals, due to the quick recovery in temperature, this is not significant, however, during shorter anneals this may be significant. In addition, for very short anneals the time taken for the specimen temperature to increase will also be substantial compared to the total anneal time. Thus, for the 2-second anneals, presented in Section IV, the actual temperature of the specimen during anneal is likely to have been significantly lower than the set temperature of the hot plate.

The overall processing methodology for the specimens in this work is shown in Fig 1.

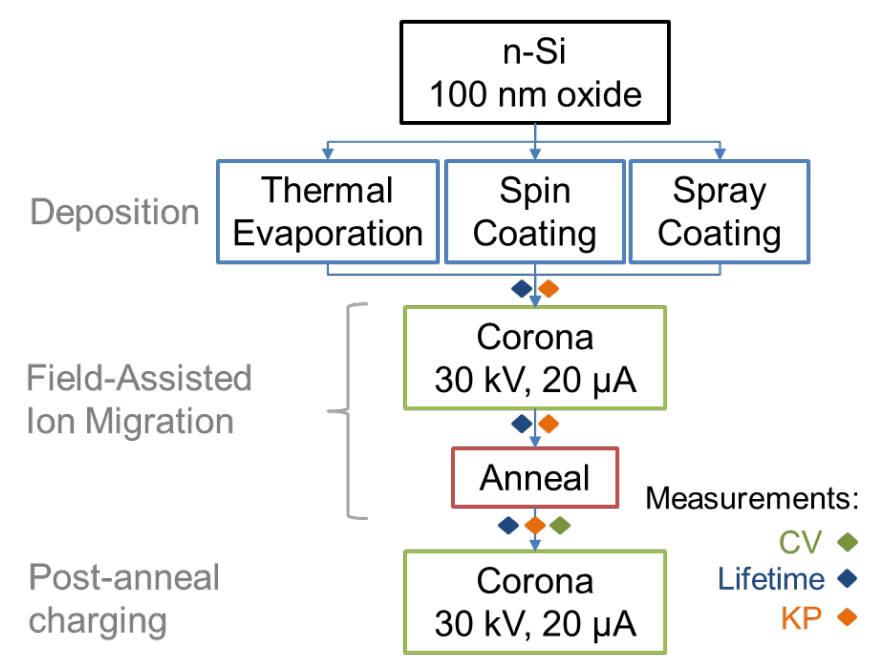

Fig 1. Experimental process flow chart

The migration of ions, and their ability to provide FEP, was characterised by the effective lifetime, which was measured throughout the processing sequence, as indicated in Fig 1. Photoconductance decay measurements (PCD) were carried out using a Sinton WCT120 tester to measure the minority carrier effective lifetime, $\tau_{e f f}$. All effective lifetime values quoted are at an injection level of $\Delta n=10^{15} \mathrm{~cm}^{-3}$.

In order to quantify the quality of the surface passivation under study, the measured effective lifetimes are often converted into a surface recombination velocity (SRV), which is independent of sample thickness. Values for SRV are derived using work by Luke and Cheng [20], and using the solution developed by Sproul [21], as: 
$S R V=\sqrt{D\left(\frac{1}{\tau_{s}}\right)} \tan \left(\frac{W}{2} \sqrt{\frac{1}{D}\left(\frac{1}{\tau_{s}}\right)}\right)$

where, $W$ is the wafer thickness, $D$ is the ambipolar carrier diffusion coefficient as a function of injection level, modelled by Klaassen [22] and taken here from PV Lighthouse's implementation [23], and $\tau_{s}$ is the surface lifetime, described by (2)

$\frac{1}{\tau_{s}}=\frac{1}{\tau_{\text {eff }}}-\frac{1}{\tau_{\text {rad }}}-\frac{1}{\tau_{\text {Aug }}}-\frac{1}{\tau_{S R H}}$

where $\tau_{\text {rad }}$ is the radiative lifetime and $\tau_{A u g}$ is the Auger lifetime, both characterised by the Richter [24] intrinsic recombination parameterisation, using radiative scaling terms $B_{\text {rel }}$ from [25] and $B_{\text {low }}$ from [26]. $\tau_{S R H}$ is the defect-mediated recombination in the bulk, characterised by Shockley, Read [27] and Hall [28] (SRH) statistics, which, for the purpose of this work, has been disregarded since FZ wafers have been used where bulk SRH recombination is very low. While it must be noted that in recent years this assumption has been shown to be invalid under certain processing conditions, such conditions were not used for this work [29]-[32].

Alongside SRV values, the surface saturation current density $\left(\mathrm{J}_{0 \mathrm{~s}}\right)$ is also used as a metric to describe the surface recombination [33]. It is useful as it is independent of doping concentration for most practical conditions. The $\mathrm{J}_{0 \mathrm{~s}}$ is calculated as reported in [34], using an iterative procedure proposed by Kimmerle et al. [35], based on the work of Mäckel and Varner [36], and Kane and Swanson [37]. In order to calculate $\mathrm{J}_{0 \mathrm{~s}}$, the effective intrinsic carrier concentration was calculated using the PV lighthouse [23] implementation of Pässler's model [38].

The interface charge concentration of ions was calculated from mercury probe capacitance-voltage (CV) measurements. For these calculations it was assumed that the charge acts as a plane within the dielectric. This plane was assumed to sit at the $\mathrm{SiO}_{2}-\mathrm{Si}$ interface as oxide back-etching experiments have shown that the charge is confined to within $10 \mathrm{~nm}$ of the $\mathrm{SiO}_{2}$ $\mathrm{Si}$ interface [15]. Both KP and CV techniques were carried out as described in [39]. If residual surface corona charge is measured during a KP reading, this will not impact the CV measurements taken afterwards as the mercury used as the top contact neutralises any residual surface corona charge. To prepare samples for $\mathrm{CV}$ measurements, a scribe was used to scratch the oxide from the back surface before creating an ohmic contact to the silicon substrate using Ga-In eutectic and silver dag.

In a subset of samples, corona charge was added after ion migration to optimise the FEP of the sample and find the maximum achievable effective lifetime. This additional corona charge was used to determine, firstly, whether FEP induced by the ions was optimum, and, secondly, whether there had been any change in the chemical passivation, normally demonstrated as a degradation in the maximum effective lifetime of the sample. This could be achieved by comparing the maximum effective lifetime to that of a corona charged control that had not undergone ion deposition or field-assisted ion migration.

\section{IONIC DEPOSITION FOR FIELD EFFECT PASSIVATION}

There are two stages of ion introduction: deposition and migration. Field-assisted ion migration was achieved by depositing corona charge on the surface before a thermal treatment.

The ions are deposited in uniform, sub-monolayer concentrations from which the cations can be migrated into the dielectric. If the ions agglomerate into crystals then release of the ions is more difficult. Thus, any deposition technique used should supress the formation of salt crystals on the dielectric surface. This is an important challenge in identifying suitable deposition techniques. Throughout this paper, the term fieldassisted ionic migration is used to refer to the combined process of corona deposition and anneal. The interface charge concentration was controlled by varying the surface corona charge deposited for the field-assisted ionic migration process, as is investigated in Section IV.A.

\section{A. Ion Deposition by Thermal Evaporation}

Thermal evaporation was used to deposit a well-defined sub-monolayer concentration of $\mathrm{KCl}$ on the oxide surface. This technique was taken as the baseline to evaluate the proposed deposition techniques. The effective lifetimes and $\mathrm{SiO}_{2}-\mathrm{Si}$ interface charge concentrations with thermally evaporated and field-assisted migration of $\mathrm{K}^{+}$ions are shown in Fig 2 along with the effective lifetimes before ion deposition, which are labelled as "initial". It is evident that this technique provides very effective FEP, as indicated by effective lifetimes increasing from $100 \mu \mathrm{s}$ to $\sim 2100 \mu \mathrm{s}$. The amount of interface charge produced in different specimens was varied by changing the amount of corona charge deposited. This will be explored in detail in Section IV. The resulting interface charge ranges from 1.5 to $2.8 \times 10^{12} \mathrm{q} / \mathrm{cm}^{2}$, which includes values of dielectric charge necessary for highquality FEP as modelled in [40]. The effective lifetimes produced with these quantities of ionic interface charge are all similar, despite an increase in FEP caused by the increasing interface charge.

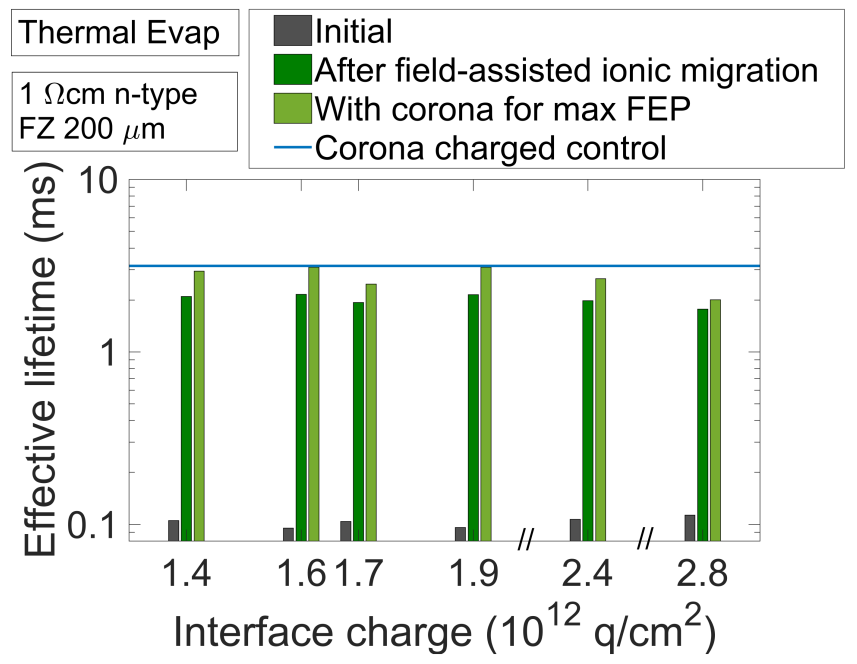

Fig 2. Effective lifetimes before (initial) and after field-assisted ionic migration with thermally deposited $\mathrm{KCl}$ as a function of interface charge concentration. Lifetime after field-assisted ion migration, with the addition of surface corona charge for maximum FEP. The horizontal line represents the 
lifetime of an as-received sample with surface corona charge for maximum FEP. FZ n-type Si, $1 \Omega \mathrm{cm}, 200 \mu \mathrm{m}, 100 \mathrm{~nm}$ thermal oxide. The migration anneal was performed at $450{ }^{\circ} \mathrm{C}$ for 1 minute.

After processing, the samples were corona charged to maximum FEP. Most of the samples, with the addition of corona charge, reached a comparable effective lifetime to that of the corona charge control, indicating that the chemical passivation had not been compromised, with the exception of the sample with the highest concentration of interface charge. For this sample, the effective lifetime with maximised FEP from the addition of surface corona, is lower than that of the control. This may indicate that ionic species at the $\mathrm{SiO}_{2}-\mathrm{Si}$ interface at these high concentrations may be damaging the chemical passivation of the surface. This is in agreement with results in [15], [41]. Additionally, it is possible that edge recombination [42] could limit the effective lifetimes of theses samples. Because the samples were cleaved to be $3 \mathrm{~cm} \times 3 \mathrm{~cm}$, it is possible that the highly recombination-active edge of the sample approached the sensor region of the lifetime tester. This effect has been noted previously [43]-[45], and is especially important when the edge of the sample is within one minority carrier diffusion length from the sensor region.

The effective lifetimes and interface charge concentrations presented in this section are now compared to those produced by the techniques with industrial potential.

\section{B. Ion Deposition by Spin Coating}

Oxidised silicon samples were spin coated with $\mathrm{KCl}$ precursor ions. The effective lifetimes before and after, and interface charge concentrations after, field-assisted ionic migration for these samples are shown in Fig 3.

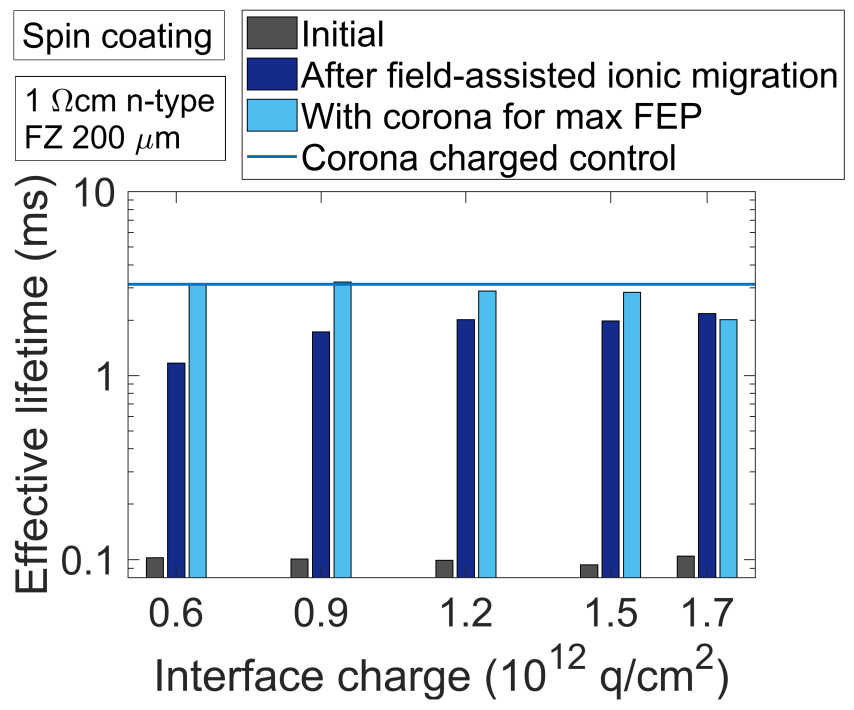

Fig 3. Effective lifetimes before (initial) and after field-assisted ionic migration with spin coated $\mathrm{KCl}$ as a function of interface charge concentration. Lifetime after field-assisted ion migration, with the addition of surface corona charge for maximum FEP. The horizontal line represents the lifetime of an as-received sample with surface corona charge for maximum FEP. FZ n-type Si, $1 \Omega \mathrm{cm}, 200 \mu \mathrm{m}, 100 \mathrm{~nm}$ thermal oxide. The migration anneal was performed at $450^{\circ} \mathrm{C}$ for 1 minute.

The presence of interface charge, shown in Fig 3, indicates that spin coating deposition is capable of delivering the precursor in sub-monolayer concentrations and that the formation of salt crystals on the oxide surface is suitably avoided.

In Fig 3, lower concentrations of interface charge were introduced compared to Fig 2. The purpose of this was to find the interface charge concentration that provides the highest quality surface passivation, and therefore the greatest effective lifetime. At the given interface charge concentrations, the effective lifetimes increase continually, reaching $2100 \mu$ s at $1.7 \times 10^{12} \mathrm{q} / \mathrm{cm}^{2}$, a very similar lifetime to that of the thermally evaporated sample with a similar interface charge. This effective lifetime is equivalent to the SRV improving significantly from $101 \mathrm{~cm} / \mathrm{s}$ to $3.3 \mathrm{~cm} / \mathrm{s}$ and gives a $\mathrm{J}_{0 \mathrm{~s}}$ of 8.4 $\mathrm{fA} / \mathrm{cm}^{2}$.

After field-assisted ionic migration, the samples are corona charged to maximise FEP, which is shown in Fig 3. For interface charge concentrations $<1.5 \times 10^{12} \mathrm{q} / \mathrm{cm}^{2}$, the effective lifetimes are similar to that of the control, indicating that ionic FEP is effective and that there is no substantial damage to the chemical passivation. However, at a charge concentration of $1.7 \times 10^{12} \mathrm{q} / \mathrm{cm}^{2}$, the lifetime with the addition of corona charge for maximum FEP does not improve.

From Fig 3, it is clear that spin coating as an ion precursor technique is capable of providing high quality surface passivation.

\section{Ion Deposition by Spray Coating}

Although spin coating is an effective technique to deliver precursor ions to the oxide surface, spray coating has the potential to be a faster, inline process. Samples were spray coated with $\mathrm{KCl}$ using a high-performance ultrasonic coating system. $\mathrm{K}^{+}$ions were subsequently introduced into the oxide using field-assisted migration.

Effective lifetimes before and after, and interface charge concentration after, field-assisted ionic migration are shown in Fig 4. Due to limited material, only one interface charge concentration was used.

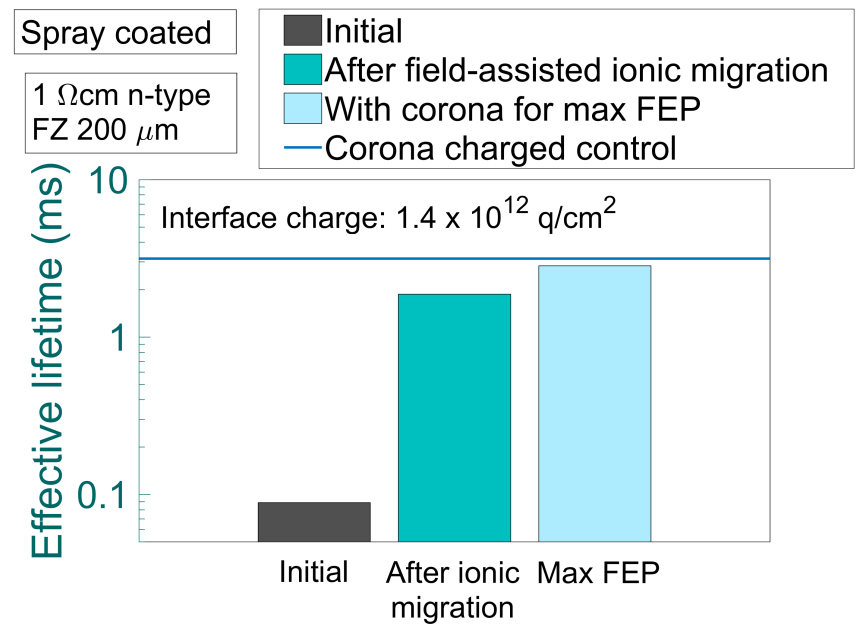

Fig 4. Effective lifetimes before (initial) and after field-assisted ionic migration with spray coated $\mathrm{KCl}$ as a function of interface charge concentration. Lifetime after field-assisted ion migration, with the addition of surface corona charge for maximum FEP. The horizontal line represents the lifetime of an as-received sample with surface corona charge for maximum 
FEP. FZ n-type Si, $1 \Omega \mathrm{cm}, 200 \mu \mathrm{m}, 100 \mathrm{~nm}$ thermal oxide. The migration anneal was performed at $450{ }^{\circ} \mathrm{C}$ for 1 minute.

It is evident that spray deposition followed by field-assisted ion migration is successful at introducing the $\mathrm{K}^{+}$ions, improving the surface passivation and giving a lifetime of $1870 \mu \mathrm{s}$, equivalent to an SRV of $4.1 \mathrm{~cm} / \mathrm{s}$ and a $\mathrm{J}_{0 \mathrm{~s}}$ of 8.6 $\mathrm{fA} / \mathrm{cm}^{2}$. For a spin coated sample with the same interface charge, the lifetime is $\sim 2000 \mu \mathrm{s}$, which is comparable.

\section{Discussion}

As seen in Fig 2 and Fig 3, the effective lifetimes achieved by both spin and spray coating are comparable to one another and to those from thermal evaporation of the precursor, which is promising for industrial application.

It appeared in Fig 2 and Fig 3 that as the concentration of ionic species at the $\mathrm{SiO}_{2}-\mathrm{Si}$ interface increased, they may be causing some damage to the chemical passivation. This was postulated based on the evidence that the effective lifetimes did not continue to increase with interface charge concentrations exceeding $\sim 1.9 \times 10^{12} \mathrm{q} / \mathrm{cm}^{2}$.

In order to assess how industrially-suitable a technique for ionic field effect passivation is, the spatial uniformity of the ions introduced must be considered.

The uniformity of the interface charge concentration was measured by cleaving samples already processed using fieldassisted ionic migration, that were $3 \mathrm{~cm} \times 3 \mathrm{~cm}$ in size, into $\sim 16$ pieces. These samples were then prepared for mercury probe $\mathrm{CV}$ measurements. Half of the samples were prepared to measure one surface, and the other half of the samples were prepared to measure the other surface. The variation in interface charge measurements across each sample is presented in Fig 5, for all three deposition techniques. The average interface charge is different for each sample due to the field-assisted ionic migration parameters that were used when processing each sample.

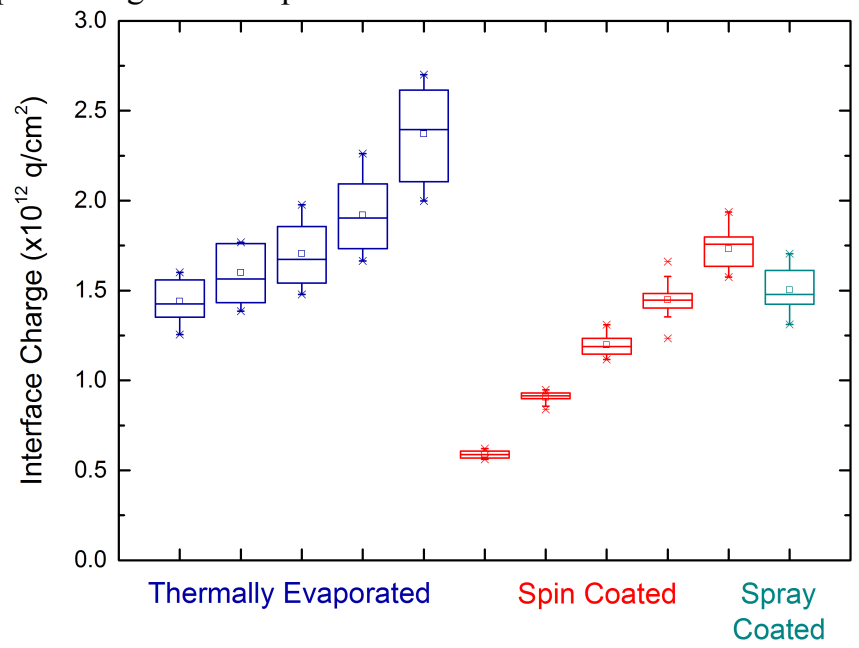

Fig 5. Box plots to show statistical data for interface charge concentration. All three deposition techniques shown. Five different average interface charge concentrations are displayed for thermal evaporation and spin coating to show the statistical distribution using different field-assisted ionic migration parameters, resulting in differing average interface charge concentrations. The interface charge concentrations are measured across both surfaces of $3 \mathrm{~cm} \mathrm{x} 3$ $\mathrm{cm}$ samples. All three precursor deposition techniques are presented. Lines of the box represent the median, lower and upper quartile values, indicates the mean and $\times$ marks the minimum and maximum values.

From the data in Fig 5, it is clear that spin coating and spray coating ion precursor deposition techniques provide very uniform interface charge concentrations. These two techniques appear to be more uniform than the thermal evaporation technique.

\section{FIELD-AsSisted IONIC MigRATION}

Spin coating and spray coating processes offer promising, commercially-suitable techniques for ion precursor deposition. However, the deposition is not the only aspect to introducing ionic field effect passivation. A commercially suitable technique to migrate the ions into the dielectric films is also required.

In the previous section, corona-induced field-assisted ionic migration, as described in Section II, was successfully employed. The process had been shown to be an effective technique to introduce ionic charge, and is preferable to simple annealing due to time savings [9], [46].

For commercial applications, it is important to identify any migration characteristics that would affect the migrated ion concentration, as well as to understand how quickly charge can be introduced. Firstly, the dependence of interface charge on initial surface corona charge concentration is discussed.

\section{A. Dependence of interface charge on the initial surface corona charge concentration}

It is postulated that the effect of surface corona charge concentration on the resulting concentration of interface charge is as follows. Immediately after ionic precursor deposition, the sample has a neutral surface due to the presence of both $\mathrm{K}^{+}$and $\mathrm{Cl}^{-}$ions in equal measure. Under these conditions, the in-diffusion of $\mathrm{K}^{+}$ions is very slow, even at $\sim 450{ }^{\circ} \mathrm{C}$ [15]. When corona charge is deposited on the oxide surface, the presence of this charge creates an electric field across the oxide layer. This electric field encourages the migration of positive ions away from the oxide surface, to the $\mathrm{SiO}_{2}$-Si interface. This ensures rapid motion of the ions after injection. As each $\mathrm{K}^{+}$ion successfully leaves the surface and migrates to the $\mathrm{SiO}_{2}-\mathrm{Si}$ interface, it leaves behind a $\mathrm{Cl}^{-}$ion on the $\mathrm{SiO}_{2}$ surface. This $\mathrm{Cl}^{-}$ion compensates a positive corona molecule and the net surface charge is reduced by one electronic charge. This leads to a reduction in the electric field across the oxide. Once the total number of $\mathrm{K}+$ ions that have reached the $\mathrm{SiO}_{2}-\mathrm{Si}$ interface is equal to the deposited surface corona charge, the electric field enhancement effect of ion injection is removed, and the process will return to the very slow diffusion process.

In order to test this hypothesis and evaluate interface charge dependence on concentration of deposited surface corona charge, samples of approximately $1 \mathrm{~cm}$ x $1 \mathrm{~cm}$ were cleaved from samples that had been deposited with ionic precursor either by thermal evaporation or by spin coating. These small samples had various quantities of corona charge deposited. The samples were then annealed on a hot plate at $450{ }^{\circ} \mathrm{C}$ for 
$60 \mathrm{~s}$, which was sufficient time for the surface charge concentration to reduce to negligible. Carrier lifetimes were not recorded due to the sample size. The interface charge concentration as a function of corona charge is shown in Fig 6 for different precursor depositions. The data show a linear relationship between interface charge and corona charge.

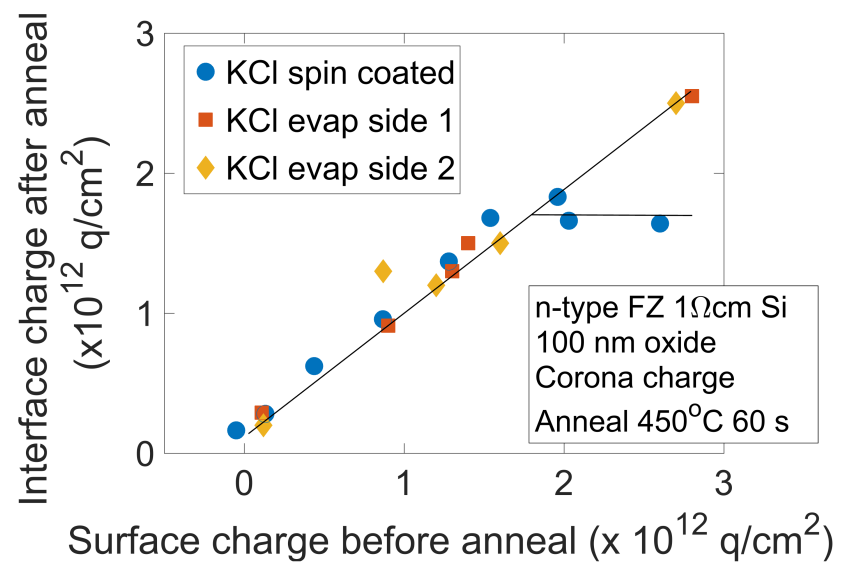

Fig 6. Interface charge concentration dependence on surface corona charge concentration before migration anneal. Shown for various precursor depositions using both thermal evaporation and spin coating techniques.

From Fig 6 it is clear that the hypothesis holds as there is an almost one-to-one relationship between the surface corona charge concentration before the migration anneal and the interface charge concentration measured afterwards. The results deviate slightly from a true one-to-one relationship. This could be due to corona charge leakage or neutralisation (by mechanisms other than movement of the $\mathrm{K}^{+}$ions) during the anneal or to insufficient anneal time meaning that the process is incomplete, and a small net concentration of positive charge was still present on the oxide surface. For the spin coated sample, the interface charge concentration plateaus at $\sim 2 \times 10^{12} \mathrm{q} / \mathrm{cm}^{-2}$ which is close to the concentration of potassium ions in the salts initially deposited.

This relationship allows the concentration of interface charge to be controlled by the concentration of corona charge deposited before the anneal. This implies interface charge can be controlled in two ways. Either by the amount of corona charge deposited, if there is a surplus of ions on the surface, or by the concentration of ions deposited if a surplus of corona charge is available.

\section{B. Anneal Temperature and Time}

Having established the relationship between surface corona charge concentration and resulting interface charge, it was necessary to investigate the relationship between anneal parameters and interface charge, and more importantly its surface passivation. One of the main drivers for investigating this is that, industrially, low temperatures and fast processes are preferable because they decrease costs by requiring lower cleanliness standards and allowing greater throughput.

Thermally oxidised samples of $3 \mathrm{~cm} \times 3 \mathrm{~cm}$ were deposited with thermally evaporated $\mathrm{KCl}$, deposited with corona charge and annealed at four temperatures: $250{ }^{\circ} \mathrm{C}, 300{ }^{\circ} \mathrm{C}, 350{ }^{\circ} \mathrm{C}$ and
$450{ }^{\circ} \mathrm{C}$ for anneal times of 2, 120 and 180 seconds. It is noted that for the two-second anneal the experimental parameters of time and temperature are subject to large measurement errors due to the difficulty in controlling the experiment for such short time periods. For the anneal of two-seconds the time and temperature should be treated as indicative values only due to the initial reduction in temperature described in Section II.. As a control, an as-received oxidised sample was deposited with corona charge and this was annealed for 3 minutes at $300{ }^{\circ} \mathrm{C}$. A set quantity of corona charge was deposited on the surfaces of all samples prior to annealing to give a surface corona charge concentration of $1.9 \times 10^{12} \mathrm{q} / \mathrm{cm}^{2}$. This concentration was selected as it was shown in Fig 6 to cause an interface charge of $\sim 1.7 \times 10^{12} \mathrm{q} / \mathrm{cm}^{2}$, and in Fig 3 produced the highest effective lifetime. This quantity of interface charge has also been shown to provide outstanding effective lifetimes and FEP previously [18].

During the lower temperature anneals, not all the surface corona charge dissipated during the anneal, so immediately after processing some corona remained on the oxide surface. This is in line with the suggested model, as the rate of neutralisation of the surface corona charge will be limited by the rate of injection of the $\mathrm{K}^{+}$ionic species into the oxide layer at lower temperatures. The residual surface corona charge would have provided an element of FEP, thus increasing the effective lifetime. Therefore, the samples were dipped into grounded IPA to remove this residual surface charge. The effective lifetimes, with no residual surface corona charge, and the interface charge after field-assisted ionic migration at each temperature for the anneal times are shown in Fig 7. Error bars represent three standard deviations of the interface charge uniformity data taken from Fig 5.

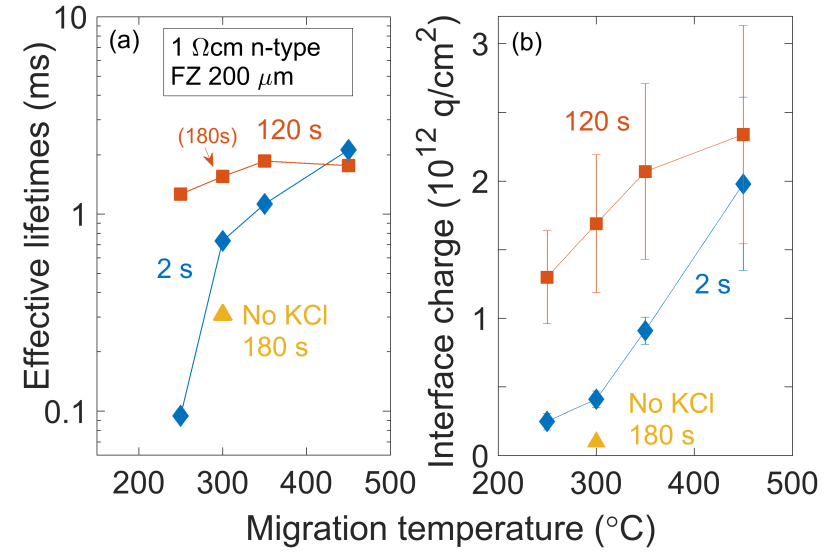

Fig 7. (a) Effective lifetimes and (b) interface charge after corona-induced field-assisted ionic migration of thermally evaporated potassium precursor using a surface corona charge concentration of $1.9 \times 10^{12} \mathrm{q} / \mathrm{cm}^{2}$ with varying anneal temperature for two anneal times. Effective lifetimes shown are with no residual surface corona charge. Error bars show $\pm 3 \sigma$ of interface charge uniformity, taken from results shown in Fig 5.

The control, with no $\mathrm{KCl}$, was treated with the same surface corona charge concentration and a migration anneal at $300{ }^{\circ} \mathrm{C}$. Fig 7 shows an increase in the control effective lifetime, but an almost negligible interface charge. It is possible that the sample, as-received, had higher chemical passivation than the other samples shown in Fig 7, as they came from different 
wafers. Alternatively, it is possible that a 3 minute anneal at $300{ }^{\circ} \mathrm{C}$, could be improving the chemical passivation at the $\mathrm{SiO}_{2}-\mathrm{Si}$ interface by facilitating bond re-formation.

\section{1) Discussion}

From Fig 7 (b) it is clear that at higher migration anneal temperatures, it is possible to achieve higher concentrations of interface charge. This is because, in the time allowed, a greater proportion of $\mathrm{K}^{+}$ions are able to overcome the activation energy to enter the $\mathrm{SiO}_{2}$. This is particularly prominent during the short anneal time when the system is far from reaching equilibrium.

The effective lifetimes of the samples, shown in Fig 7 (a), increase with anneal temperature, indicating that the surface passivation is increasing in this range of interface charge concentration. The temperatures investigated here are all appropriate for oxidised silicon processing under typical laboratory conditions and do not require special cleanroom conditions.

Fig 7 (b) shows that ions are introduced in under two seconds on the hotplate. At $450{ }^{\circ} \mathrm{C}$, a migration anneal of two seconds is seen to be sufficient to introduce an interface charge concentration comparable to a migration anneal of 120 seconds. This two-second anneal at $450{ }^{\circ} \mathrm{C}$ provides the highest effective lifetime in Fig 7 (a), indicating that it provides the highest quality surface passivation. It is possible that the ionic introduction occurred in an even shorter anneal time. A nominally two-second anneal is extremely quick, and very promising for developing a rapid process for industrially introducing ionic FEP.

Within the silicon PV industry, there has been concern over potential induced degradation (PID), however it is unlikely that the ionic field effect technique will contribute to it. PID is caused by the potential difference between the module frame and the silicon [47]. This potential difference can cause sodium ions from the module glass to migrate into the emitter. These ions can decorate stacking faults within the silicon and cause shunting losses that degrade cell performance [48]-[50]. However, in recent years, techniques have been developed to prevent PID [51]-[53]. The solution involves the minimisation of the electric field across the antireflection coating and thus, will reduce the migration of ions, either from the glass or from the proposed ionic passivation, into the emitter. For this reason, the authors believe that ionic field effect passivation will not be affected by, or contribute towards PID.

\section{CONCLUSIONS}

This work demonstrates a fast, scalable and effective method to improve the field effect passivation of a $\mathrm{SiO}_{2}-\mathrm{Si}$ interface by the introduction of ions to the dielectric. Ions are deposited by spin or spray coating and transported in seconds using field-assisted ionic migration. The results show that both spin and spray coating allow the precursor to be deposited on the oxide in a suitable manner, such that ions can migrate. Moreover, the results show big improvements to standard oxide passivation, using scalable, industrially appropriate techniques. This process has been seen to reduce the SRV of 1 $\Omega \mathrm{cm} \mathrm{Si}$, from $100 \mathrm{~cm} / \mathrm{s}$ to $3.3 \mathrm{~cm} / \mathrm{s}$, equivalent to a $J_{0 .}$ of 8.4 $\mathrm{fA} / \mathrm{cm}^{2}$. It is clear that field-assisted ionic migration using corona charge is a rapid, effective technique to enhance FEP, requiring a migration anneal of under 2 seconds at $450{ }^{\circ} \mathrm{C}$. If exploited, this technique has the potential to improve current methods of surface passivation of silicon, allowing tailored, extrinsic field effect passivation to be applied in a matter of seconds.

\section{REFERENCES}

[1] M. A. Green, "Commercial progress and challenges for photovoltaics,” Nat. Energy, vol. 1, no. 1, p. 1, 2016.

[2] W. D. Eades and R. M. Swanson, "Determination of the capture cross section and degeneracy factor of $\mathrm{Si}-\mathrm{SiO} 2$ interface states," Appl.Phys. Lett., vol. 44, no. 10, pp. 988-990, 1984.

[3] G. Bourret-Sicotte et al., "Shielded hydrogen passivation - A potential in-line passivation process," Phys. Status Solidi, vol. 1700383, 2017.

[4] A. Ebong, P. Doshi, S. Narasimha, A. Rohatgi, J. Wang, and M. A. El-Sayed, "The Effect of Low and High Temperature Anneals on the Hydrogen Content and Passivation of Si Surface Coated with SiO2 and SiN Films," J. Electrochem. Soc., vol. 146, no. 5, pp. 1921-1924, 1999.

[5] A. Cuevas, T. Allen, and J. Bullock, "Skin care for healthy silicon solar cells," 2015 IEEE 42nd Photovolt. Spec. Conf., no. 1, pp. 1-6, 2015.

[6] R. S. Bonilla, C. Reichel, M. Hermle, P. Hamer, and P. R. Wilshaw, "Long term stability of c-Si surface passivation using corona charged SiO2,” Appl. Surf. Sci., vol. 412, pp. 657-667, 2017.

[7] S. W. Glunz, D. Biro, S. Rein, and W. Warta, "Field-effect passivation of the SiO2-Si interface," J. Appl. Phys., vol. 86, no. 1, p. $683,1999$.

[8] J. Schmidt and A. G. Aberle, "Easy-to-use Surface Passivation Technique for Bulk Carrier Lifetime Measurements on Silicon Wafers," Prog. Photovoltaics Res. Appl., vol. 263, no. January, pp. 259-263, 1998

[9] R. S. Bonilla and P. R. Wilshaw, "Potassium ions in SiO2: Electrets for silicon surface passivation," J. Phys. D. Appl. Phys., vol. 51, no. 2, 2018.

[10] R. Hezel and K. Jaeger, "Low-Temperature Surface Passivation of Silicon for Solar Cells," J. Electrochem. Soc., vol. 136, no. 2, pp. 518-523, 1989.

[11] R. Hezel, K. Blumenstock, and R. Schorner, "Interface States and Fixed Charges in MNOS Structures with APCVD and Plasma Silicon Nitride," J. Electrochem. Soc., 1984.

[12] K. Jager and R. Hezel, "Optical Stability of Silicon Nitride MIS Inversion Layer Solar Cells," IEEE Trans. Electron Devices, vol. 32, no. 9, pp. 1824-1829, 1985.

[13] M. Goldman, a. Goldman, and R. S. Sigmond, "The corona discharge, its properties and specific uses," Pure Appl. Chem., vol. 57, no. 9, pp. 1353-1362, 1985.

[14] J. S. Chang, P. A. Lawless, and T. Yamamoto, "Corona Discharge Processes," IEEE Trans. Plasma Sci., vol. 19, no. 6, pp. 1152-1166, 1991.

[15] R. S. Bonilla and P. R. Wilshaw, "A technique for field effect surface passivation for silicon solar cells," Appl. Phys. Lett., vol. 
104, 2014.

[16] W.-C. Cheng et al., "Investigation of rear $\mathrm{SiOx} / \mathrm{SiNx}$ passivated solar cells under low irradiance intensities," 2014 IEEE 40th

Photovolt. Spec. Conf., no. 3, pp. 2459-2462, 2014.

[17] S. Duttagupta, Z. Hameiri, T. Grosse, D. Landgraf, B. Hoex, and A. G. Aberle, "Dielectric Charge Tailoring in PECVD SiOx/SiNx Stacks and Application at the Rear of the Al Local Back Surface Field Si Wafer Solar Cells," Photovoltaics, IEEE J., vol. 5, no. 4, pp. 1014-1019, 2015.

[18] K. A. Collett et al., "An enhanced alneal process to produce SRV under $1 \mathrm{~cm} / \mathrm{s}$ in $1 \Omega \mathrm{cm}$ n-type Si," Sol. Energy Mater. Sol. Cells, vol. 173, 2017.

[19] Z. Luo, K. A. Collett, S. Du, P. Hamer, R. S. Bonilla, and P. R. Wilshaw, "On the formation and stability of potassium-ion $\mathrm{SiO} 2$ electrets," Electrochem. Soc. J. Solid State Sci. Technol. (under submission).

[20] K. L. Luke and L. J. Cheng, "Analysis of the interaction of a laser pulse with a silicon wafer: Determination of bulk lifetime and surface recombination velocity," J. Appl. Phys., vol. 61, no. 6, pp. 2282-2293, 1987.

[21] A. B. Sproul, "Dimensionless solution of the equation describing the effect of surface recombination on carrier decay in semiconductors," J. Appl. Phys., vol. 76, no. 5, pp. 2851-2854, 1994.

[22] D. B. M. Klaassen, "A unified mobility model for device simulation-II. Temperature dependence of carrier mobility and lifetime," Solid State Electron., vol. 35, no. 7, pp. 961-967, 1992.

[23] "PV Lighthouse." [Online]. Available: https://www.pvlighthouse.com.au/.

[24] A. Richter, S. W. Glunz, F. Werner, J. Schmidt, and A. Cuevas, "Improved quantitative description of Auger recombination in crystalline silicon," Phys. Rev. B - Condens. Matter Mater. Phys., vol. 86, no. 16, pp. 1-14, 2012.

[25] P. P. Altermatt, F. Geelhaar, T. Trupke, X. Dai, A. Neisser, and E. Daub, "Injection dependence of spontaneous radiative recombination in c-Si: Experiment, theoretical analysis, and simulation," NUSOD '05 - Proc. 5th Int. Conf. Numer. Simul. Optoelectron. Devices, vol. 2005, no. 2, pp. 47-48, 2005.

[26] T. Trupke et al., "Temperature dependence of the radiative recombination coefficient of intrinsic crystalline silicon," J. Appl. Phys., vol. 94, no. 8, pp. 4930-4937, 2003.

[27] W. Shockley and W. T. Read, "Statistics of the Recombination of Holes and Electrons," Phys. Rev., vol. 87, no. 46, pp. 835-842, 1952.

[28] R. N. Hall, "Electron-hole recombination in Geranium," Phys. Rev., vol. 175, no. 3, pp. 823-840, 1968.

[29] N. E. Grant, V. P. Markevich, J. Mullins, A. R. Peaker, F. Rougieux, and D. Macdonald, "Thermal activation and deactivation of grown-in defects limiting the lifetime of float-zone silicon," Phys. Status Solidi - Rapid Res. Lett., vol. 10, no. 6, pp. 443-447, 2016.

[30] N. E. Grant, F. E. Rougieux, and D. MacDonald, "Low Temperature Activation of Grown-In Defects Limiting the Lifetime of High Purity n-Type Float-Zone Silicon Wafers," Solic State Phenom., vol. 242, pp. 120-125, 2016.

[31] N.E. Grant et al., "Permanent annihilation of thermally activated defects which limit the lifetime of float-zone silicon," Phys. Status Solidi Appl. Mater. Sci., vol. 213, no. 11, pp. 2844-2849, 2016.
[32] T. Niewelt et al., "Taking Monocrystalline Silicon to the Ultimate Lifetime Limit (In Press),” Sol. Energy Mater. Sol. Cells, 2018.

[33] K. R. McIntosh and L. E. Black, "On effective surface recombination parameters," J. Appl. Phys., vol. 116, no. 1, 2014.

[34] R. S. Bonilla, B. Hoex, P. Hamer, and P. R. Wilshaw, "Dielectric surface passivation for silicon solar cells: A review," Phys. Status Solidi (a), vol. 214, no. 7, 2017.

[35] A. Kimmerle, J. Greulich, and A. Wolf, "Carrier-diffusion corrected $\mathrm{J} 0$-analysis of charge carrier lifetime measurements for increased consistency," Sol. Energy Mater. Sol. Cells, vol. 142, pp. 116-122, 2015.

[36] H. Mäckel and K. Varner, "On the determination of the emitter saturation current density from lifetime measurements of silicon devices," Prog. Photovolt Res. Appl., vol. 21, pp. 850-866, 2013.

[37] D. E. Kane and R. M. Swanson, "Mesaurement of the Emitter Saturation Current by a Contactless Photoconductivity Decay Method," in Proceedings of the 18th IEEE Photovoltaic Specialists Conference, 1985, pp. 578-583.

[38] R. Pässler, "Semi-empirical descriptions of temperature dependences of band gaps in semiconductors," Phys. Status Solidi Basic Res., vol. 236, no. 3, pp. 710-728, 2003.

[39] R. S. Bonilla, N. Jennison, D. Clayton-Warwick, K. A. Collett, L. Rands, and P. R. Wilshaw, "Corona charge in SiO2: kinetics and surface passivation for high efficiency silicon solar cells," Energy Procedia, vol. 92, pp. 326-335, 2016.

[40] R. S. Bonilla and P. R. Wilshaw, "On the c-Si/SiO2interface recombination parameters from photo-conductance decay measurements," J. Appl. Phys., vol. 121, no. 13, 2017.

[41] R. S. Bonilla, K. Collett, L. Rands, G. Martins, R. Lobo, and P. R. Wilshaw, "Stable, Extrinsic, Field Effect Passivation for Back Contact Silicon Solar Cells," Solid State Phenom., vol. 242, pp. 6772, 2015.

[42] F. J. Ma, Z. Hameiri, G. S. Samudra, M. Peters, and B. Hoex, "Numerical analysis of injection level dependent effective lifetime on $125 \mathrm{~mm}$ undiffused lifetime samples," 2014 IEEE 40th Photovolt. Spec. Conf. PVSC 2014, pp. 3313-3316, 2014.

[43] B. Veith et al., "Injection dependence of the effective lifetime of ntype Si passivated by A12O3: An edge effect?," Sol. Energy Mater. Sol. Cells, vol. 120, no. PART A, pp. 436-440, 2014.

[44] R. S. Bonilla, G. Martins, and P. R. Wilshaw, "Investigation of Parasitic Edge Recombination in High-Lifetime Oxidized n-Si," Solid State Phenom., vol. 242, pp. 73-79, 2015.

[45] M. Kessler, T. Ohrdes, P. P. Altermatt, and R. Brendel, "The effect of sample edge recombination on the averaged injection-dependent carrier lifetime in silicon,” J. Appl. Phys., vol. 111, no. 5, 2012.

[46] P. R. Wilshaw and R. S. Bonilla, "Charge Stabilized Dielectric Film for Electronic Devices," US 2016/0343884 A1, 2016.

[47] S. Pingel et al., "Potential Induced Degradation of solar cells and panels," 2010 35th IEEE Photovolt. Spec. Conf., no. November 2015, pp. 002817-002822, 2010.

[48] B. Ziebarth, M. Mrovec, C. Elsässer, and P. Gumbsch, "Potentialinduced degradation in solar cells: Electronic structure and diffusion mechanism of sodium in stacking faults of silicon," J. Appl. Phys., vol. 116, no. 9, 2014.

[49] V. Naumann et al., "Explanation of potential-induced degradation of the shunting type by Na decoration of stacking faults in Si solar cells," Sol.Energy Mater. Sol. Cells, vol. 120, no. PART A, pp. 
383-389, 2014.

[50] V. Naumann et al., "The role of stacking faults for the formation of shunts during potential-induced degradation of crystalline Si solar cells," Phys. Status Solidi - Rapid Res. Lett., vol. 7, no. 5, pp. 315$318,2013$.

[51] X. Gou et al., "Effect of Photoconductive Properties of SiN x

Passivation Film on Anti-potential Induced Degradation

Performance of Photovoltaic Cells and Modules," vol. 24, no. 2, pp. 121-125, 2018.

[52] S. M. Seutter and M. M. Moslehi, "SURFACE PASSIVATION OF HIGH-EFFICIENCY CRYSTALLINE SILICON SOLAR CELLS," US 2017/0222067 A1, 2017.

[53] W. Luo et al., "Potential-induced degradation in photovoltaic modules: A critical review," Energy and Environmental Science. 2017. 